\title{
EFFECT OF GENOTYPE AND DENSITY ON THE PRODUCTIVITY OF MUNGBEAN
}

\author{
R. Yeasmin ${ }^{1}$, M. A. Karim ${ }^{1 \star}$, M.M. Haque ${ }^{1}$ and M. A. B. Mia ${ }^{2}$ \\ ${ }^{1}$ Department of Agronomy, ${ }^{2}$ Department of Crop Botany \\ Bangabandhu Sheikh Mujibur Rahman Agricultural University, Gazipur-1706, Bangladesh \\ Corresponding Author: akarim1506@yahoo.com
}

Keywords: Grain legume, spacing, yield, light interception

\begin{abstract}
An investigation was carried out at the experimental field of the Department of Agronomy, Bangabandhu Sheikh Mujibur Rahman Agricultural University, Gazipur during September to November 2014 to evaluate the productivity of three mungbean genotypes, viz., GK-24 (G1), GK-63 (G2) and BU mug 4 (G3) under four plant spacing (densities) such as i) $15 \mathrm{~cm} \times 10 \mathrm{~cm}=66$ plants $\mathrm{m}^{-2}$ (D1), ii) $20 \mathrm{~cm} \times 10 \mathrm{~cm}=$ 50 plants $\mathrm{m}^{-2}$ (D2), iii) $25 \mathrm{~cm} \times 10 \mathrm{~cm}=40$ plants $\mathrm{m}^{-2}$ (D3) and iv) $30 \mathrm{~cm} \times 10 \mathrm{~cm}=33$ plants $\mathrm{m}^{-2}$ (D4). The experiment was conducted in a factorial randomized complete block design with three replications. A wide variation among the genotypes was observed in relation to light transmission, yield, and yield contributing characters. At $30 \mathrm{~cm} \times 10 \mathrm{~cm}$ spacing (D4) the highest light transmission ratio (LTR) was observed in G1 genotype (57.92) and the lowest LTR value in G2 genotype (46.92). Among the three genotypes, G1 produced the highest seed yield $\left(1094 \mathrm{~kg} \mathrm{ha}^{-1}\right)$. But highest seed number pod ${ }^{-1}$ was found in D2 (11.61) while maximum pods plant ${ }^{-1}(11.08)$ was in D4 treatment followed by D3 (10.59). Among the four plant densities, treatment D3 showed the highest 1000 -seed weight $(50.30 \mathrm{~g})$. The highest seed yield $(1114 \mathrm{~kg}$ ha$\left.{ }^{1}\right)$ was recorded in the treatment D4. Among the interaction, the highest number of seeds pod $^{-1}(12.20)$ was found in the treatment D1G3, though the highest number of pods plant ${ }^{-1}(12.03)$ was in treatment D4G1 but the1000-seed weight was the highest $(51.92 \mathrm{~g})$ in D3G1. The highest seed yield $\left(1230 \mathrm{~kg} \mathrm{ha}^{-1}\right)$ was recorded from treatment D4G1. The result showed that GK 24 genotype performed the best in all respects of yield and yield attributes at $30 \mathrm{~cm} \times 10 \mathrm{~cm}$ spacing compared to other treatments.
\end{abstract}

\section{Introduction}

Mungbean (Vignaradiata L. Wilczek), belongs to the family leguminosae, is an important pulse crop. It ranks fourth in production and first in respect of area of pulses cultivation in Bangladesh (BBS, 2013). As a leguminous crop it fixes atmospheric nitrogen and improves soil productivity. The yield of such an important crop in the field is very low in comparison to its potential productivity due to adverse effect of environment as well as management factors. Environment plays a vital role in mungbean productivity as reported by Allard (1990) and Eisemann, et al. (1990). Mungbean is cultivated either in late winter in southern part or in summer season in most of the other parts of Bangladesh. Recently developed short duration mungbean varieties could be successfully cultivated in wheat-rice cropping system without affecting cropping pattern after harvesting of wheat and before the transplantation of rice.

Mungbean has been expanded to the southwestern districts of Bangladesh, mostly in the aman rice - wheat - mungbean or aman rice - vegetables / potato - mungbean cropping 
Yeasmin et al.

patterns and also mungbean in rice-rice or rice-wheat system in northern districts. Plant density may vary with genotype, time of sowing, growing conditions and other environmental factors. The optimum plant population can be maintained by using adequate seed rate so obtaining high yields; optimum seed rate should be used. In Bangladesh, planting density of $30 \mathrm{~cm} \times 10 \mathrm{~cm}$ gave higher yield of mungbean than $20 \mathrm{~cm} \times 20 \mathrm{~cm}$ or $40 \mathrm{~cm} \times 30 \mathrm{~cm}$ planting density (Sarkar et al., 2004).

High variation in growth, phenology, yield attributes and grain yield among mungbean genotypes was observed by Yimram et al. (2009). Sultana (2014) noticed a significant variation in 1000-seed weight, growth duration and productivity of the genotypes. Based on the yield performance and short growth duration of mungbean genotypes, some of them have been selected. However, their management options have to be identified before making them available for cultivation by the farmers. Therefore, this study was planned to determine yield performance of three selected mungbean genotypes at different plant densities.

\section{Materials and Methods}

The experiment was carried out at the experimental field of Bangabandhu Sheikh Mujibur Rahman Agricultural University, Gazipur during September to November 2014. The experimental site is located at the centre of Madhupur Tract $\left(24^{\circ} 09 \mathrm{~N}\right.$ latitude and $90^{\circ} 26^{\prime} \mathrm{E}$ longitude) having an elevation of $8.2 \mathrm{~m}$ from sea level. The soil type of the experimental field belongs to the Shallow Red Brown Terrace type under Salna Series of Madhupur Tract of Agro ecological Zone (AEZ) 28. The experiment was carried out in a factorial RCBD design. The genotypes were: i) GK-24 (G1), ii) ii) GK-63 and iii) BU mug 4 . and the density (spacing) were: i) $15 \mathrm{~cm} \times 10 \mathrm{~cm}=66$ plants $\mathrm{m}^{-2}$ (D1), ii) $20 \mathrm{~cm} \times 10 \mathrm{~cm}=50$ plants $\mathrm{m}^{-2}$ (D2) iii) $25 \mathrm{~cm} \times 10 \mathrm{~cm}=40$ plants $\mathrm{m}^{-2}$ (D3), and iv) $30 \mathrm{~cm} \times 10 \mathrm{~cm}=33$ plants $\mathrm{m}^{-2}$ (D4). The unit plot size was $3 \mathrm{~m} \times 1 \mathrm{~m}$. At physiological maturity, dry pods were harvested at different days after sowing (DAS) for different genotypes. The harvesting was started from 63 DAS for G2 and continued up to 70 DAS for G3.Data on different morphological parameters including seed yield and yield contributing characters were recorded following standard methods. Light transmission ratio (LTR) was calculated by the following formula-

LTR = $\frac{\mathrm{I}}{\mathrm{I}_{0}}$

Where, I = Light intensity at the bottom of the crop

$\mathrm{I}_{0}=$ Light intensity at the top of crop

\section{Results and Discussion}

\section{Plant height}

At $15 \mathrm{~cm} \times 10 \mathrm{~cm}$ spacing, genotype GK 24 and BU mug 4 were statistically similar in plant height (Fig. 1). The longest plant was observed in G3 $(56.90 \mathrm{~cm})$, where GK 63 produced the shortest plant $(47.62 \mathrm{~cm})$. At $20 \mathrm{~cm} \times 10 \mathrm{~cm}$ spacing, the highest plant height was observed in G3 $(56.58 \mathrm{~cm})$ and the lowest in $\mathrm{G} 2(42.67 \mathrm{~cm})$. At $25 \mathrm{~cm} \times 10 \mathrm{~cm}$ spacing, the tallest plant was observed in G3 and the shortest plant in $\mathrm{G} 2(46.82 \mathrm{~cm})$. At $30 \mathrm{~cm} \times 10 \mathrm{~cm}$ spacing, the highest plant height was observed in $\mathrm{G} 1(53.51 \mathrm{~cm})$ and lowest in G2 (48.59 $\mathrm{cm})$. Plant height is an important morphological character of crop plant that showed positive correlation with seed yield of mungbean (Rubio et al., 2004). 


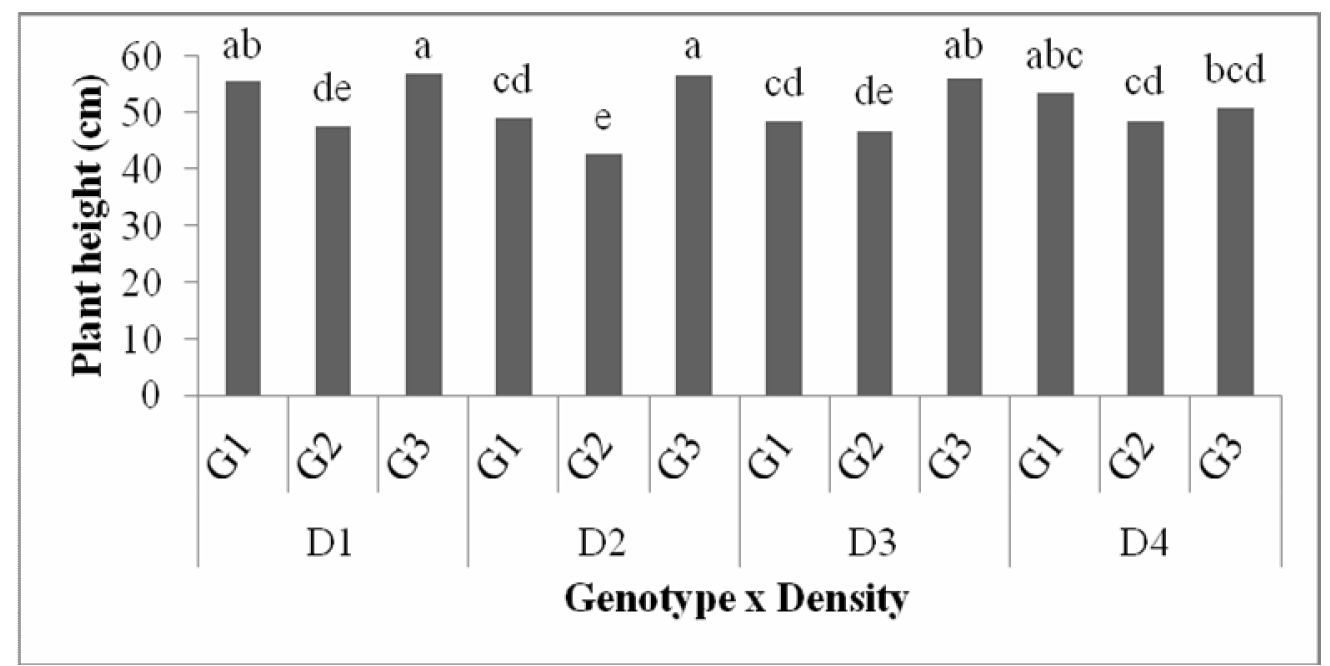

Fig.1. Variation in plant height of three mungbean genotypes grown at different plant spacing. G1: GK 24, G2: GK 63, G3: BU mug 4, $D_{1}: 15 \mathrm{~cm}$ x $10 \mathrm{~cm}, D_{2}: 20 \mathrm{~cm} \times 10$ $\mathrm{cm}, \mathrm{D}_{3}: 25 \mathrm{~cm} \times 10 \mathrm{~cm}$ and $\mathrm{D}_{4}: 30 \mathrm{~cm} \times 10 \mathrm{~cm}$

\section{Number of branch plant ${ }^{-1}$}

The maximum number of branch plant ${ }^{-1}$ was found from the widest density D4, compared to closer one (Fig. 2). The number of branch per plant was decreased with the increase of plant density in the order of $30>25>20>15 \mathrm{~cm}$. Gupta (1998) also found the similar type of findings in mustard.

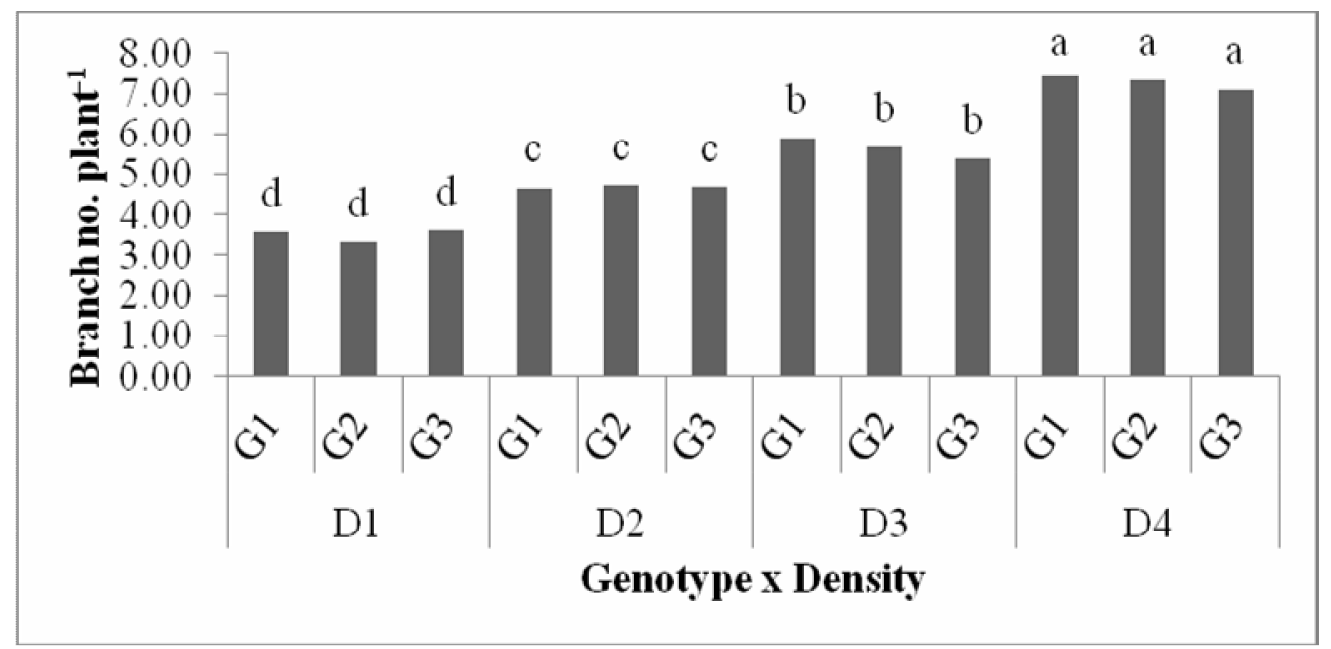

Fig. 2. Variation in branch no. plant ${ }^{-1}$ of three mungbean grown at different plant spacing. G1: GK 24, G2: GK 63, G3: BU mug 4, $D_{1}: 15 \mathrm{~cm}$ x $10 \mathrm{~cm}, D_{2}: 20 \mathrm{~cm} \times 10 \mathrm{~cm}, D_{3}$ : $25 \mathrm{~cm} \times 10 \mathrm{~cm}$ and $\mathrm{D}_{4}: 30 \mathrm{~cm} \times 10 \mathrm{~cm}$

\section{Light interception through canopy}

At $15 \mathrm{~cm} \times 10 \mathrm{~cm}$ spacing, the light transmission ratio (LTR) was the highest (27.95) in GK 24 and the lowest (14.93) in BU mug 4. At $20 \mathrm{~cm} \times 10 \mathrm{~cm}$ spacing, the highest LTR value 
Yeasmin et al.

(37.93) was observed in G1, while the lowest (32.00) in G3. At $25 \mathrm{~cm} \times 10 \mathrm{~cm}$, highest LTR value (41.34) was observed in G1 and the lowest (36.14) in G3. At $30 \mathrm{~cm} \times 10 \mathrm{~cm}$ spacing, the highest LTR value (57.92) in G1 genotype, while the lowest LTR value (46.42) was observed in G2 (Fig. 3). It was obvious that with the decrease in plant population, the light transmission ratio was increased. At D4, plant density the mungbean plants received optimum light at the lower canopy probably due to optimum plant spacing and minimum mutual shading.

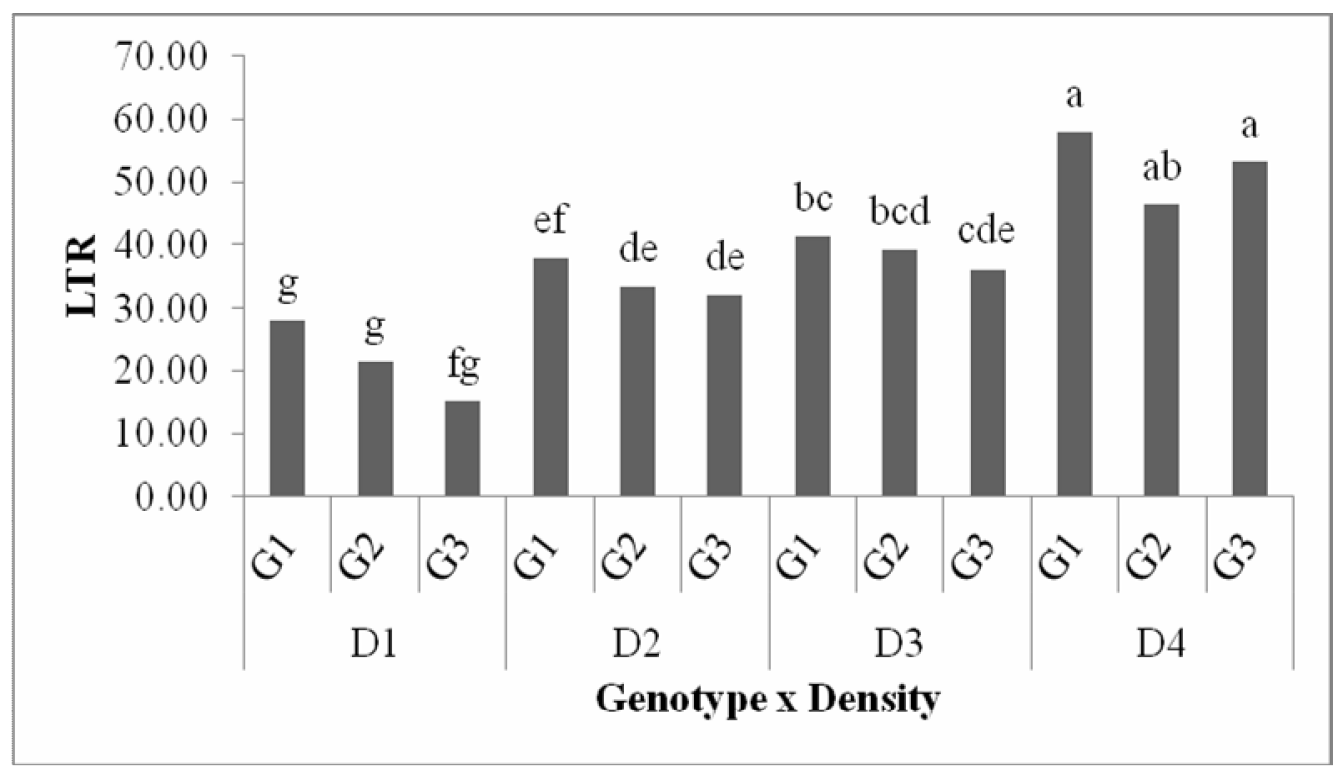

Fig. 3. Variation in light transmission ration (LTR) of three mungbean genotypes rown at different plant spacing.

G1: GK 24, G2: GK 63, G3: BU mug 4, D1:15 cm x $10 \mathrm{~cm}, \mathrm{D} 2: 20 \mathrm{~cm} \times 10 \mathrm{~cm}, \mathrm{D} 3:$ $25 \mathrm{~cm} \times 10 \mathrm{~cm}$ and D4: $30 \mathrm{~cm} \times 10 \mathrm{~cm}$

\section{Effect of genotypes on yield and yield components}

The genotypes showed variation in producing grain yield and yield contributing characters (Table 1). The maximum number of seeds $\operatorname{pod}^{-1}$ (11.77) was in G3 followed by G1 (11.63) while G2 had the lowest seeds pod $^{-1}(11.14)$. In case of no. of pods plant ${ }^{-1}$, G3 produced the highest (10.48) and G2 the lowest (9.24). 1000-seed weight was maximum (50.15 g) in G1 followed by $\mathrm{G} 2$ (49.48 g). Among the three mungbean genotypes, G1 produced the maximum seed yield (1094 $\mathrm{kg} \mathrm{ha}^{-1}$ ) followed by G3. The highest seed yield in G1 was mostly associated with 1000-seed weight and number of pods plant ${ }^{-1}$. G2 produced the lowest seed yield $\left(945 \mathrm{~kg} \mathrm{ha}^{-1}\right)$, which was due to the lowest number of pods plant ${ }^{-1}$ and seeds pod ${ }^{-1}$.

Table 1. Effect of genotypes on seed yield and yield contributing characters of mungbean genotypes

\begin{tabular}{l|l|l|c|c}
\hline Genotype & $\begin{array}{c}\text { No. of seed } \\
\text { pod }^{-1}\end{array}$ & No. of pods plant & $\begin{array}{c}\text { 1000- seed } \\
\text { wt. }(\mathrm{gm})\end{array}$ & $\begin{array}{c}\text { Seed yield } \\
\left(\mathrm{kg} \mathrm{ha}^{-1}\right)\end{array}$ \\
\hline
\end{tabular}


Effect of Genotype and Density on the Productivity of Mungbean

\begin{tabular}{lcccc}
\hline $\mathrm{G}_{1}$ & 11.63 & 10.48 & 50.15 & 1093.70 \\
$\mathrm{G}_{2}$ & 11.14 & 9.24 & 49.48 & 944.90 \\
$\mathrm{G}_{3}$ & 11.77 & 9.59 & 46.98 & 1031.80 \\
\hline $\mathrm{CV}(\%)$ & 3.81 & 9.90 & 3.20 & 2.68 \\
$\mathrm{LSD}(0.05)$ & 0.37 & 0.82 & 1.33 & 23.20 \\
\hline
\end{tabular}

Here, $\mathrm{G}_{1}$ : GK 24, $\mathrm{G}_{2}$ : GK 63 and $\mathrm{G}_{3}$ : BU mug 4

\section{Effect of plant spacing on yield and yield components}

Plant spacing did not affect significantly the number of seeds $\operatorname{pod}^{-1}$, though the maximum seed number pod ${ }^{-1}$ was found in D2 (11.61) followed by D3 (11.60), and the lowest number (11.31) in D4 treatment (Table 2). No. of pods plant ${ }^{-1}$ was recorded maximum (11.08) in D4 treatment followed by D3 (10.59); while the lowest number of pods plant ${ }^{-1}(7.88)$ in treatment D1. Plant spacing also influenced significantly the 1000-seed weight of mungbean. The treatment D3 showed the highest 1000 -seed weight $(50.30 \mathrm{~g})$, while D1 showed the lowest $(46.13 \mathrm{~g})$. The maximum seed yield $\left(1114 \mathrm{~kg} \mathrm{ha}^{-1}\right)$ was recorded in the treatment D4 followed by D3 $\left(1059 \mathrm{~kg} \mathrm{ha}^{-1}\right)$ while seed yield lowest $\left(931.9 \mathrm{~kg} \mathrm{ha}^{-1}\right)$ in D1 treatment. The highest seed yield in D3 treatment was attributed mostly due to the highest number of pods plant ${ }^{-1}$. Probably the specific plant spacing ensured optimum natural resources for plant productivity and thus produced the highest seed yield per hectare.

Table 2. Effect of density on seed yield and yield contributing characters of mungbean genotypes

\begin{tabular}{l|c|c|c|c}
\hline Density & $\begin{array}{c}\text { No. of seed } \\
\text { pod }^{-1}\end{array}$ & $\begin{array}{c}\text { No. of pods } \\
\text { plant }^{-1}\end{array}$ & $\begin{array}{c}\text { 1000- seed wt. } \\
\text { (gm) }\end{array}$ & $\begin{array}{c}\text { Seed yield } \\
\left(\mathrm{kg} \mathrm{ha}^{-1}\right)\end{array}$ \\
\hline $\mathrm{D}_{1}$ & 11.52 & 7.88 & 46.13 & 931.90 \\
$\mathrm{D}_{2}$ & 11.61 & 9.54 & 49.23 & 988.10 \\
$\mathrm{D}_{3}$ & 11.60 & 10.59 & 50.30 & 1059.80 \\
$\mathrm{D}_{4}$ & 11.31 & 11.08 & 49.82 & 1114.10 \\
\hline $\mathrm{CV}(\%)$ & 3.81 & 9.90 & 3.20 & 2.68 \\
LSD (0.05) & 0.43 & 0.95 & 1.53 & 26.79 \\
\hline
\end{tabular}

$D_{1}: 15 \mathrm{~cm} \times 10 \mathrm{~cm}, D_{2}: 20 \mathrm{~cm} \times 10 \mathrm{~cm}, \mathrm{D}_{3}: 25 \mathrm{~cm} \times 10 \mathrm{~cm}$ and $\mathrm{D}_{4}: 30 \mathrm{~cm} \times 10 \mathrm{~cm}$

\section{Genotype and density interaction effects on yield and yield components}

Interaction of mungbean genotypes and density influenced significantly on seed yield and yield contributing characters (Table 3). The maximum number of seeds pod ${ }^{-1}(12.20)$ was found in the treatment D1G3, which was followed by D2G3 (12.10). The lowest number of seeds $\operatorname{pod}^{-1}(10.60)$ was observed in the treatment D1G2. Higher number of pods plant ${ }^{1}(12.03)$ was recorded in treatment D4G1 followed by D3G1. Contrary, the lowest number of pods plant ${ }^{-1}(7.21)$ was recorded in the treatment D1G3. 1000-seed weight was significantly affected by the interaction of genotypes and plant spacing. The maximum 1000-seed weight $(51.92 \mathrm{~g})$ was recorded in the treatment D3G1, which was followed by D4G1 and D4G2. The minimum 1000-seed weight $(45.36 \mathrm{~g})$ was recorded in D1G3 treatment followed by D1G2 treatment. The highest seed yield (1230 $\left.\mathrm{kg} \mathrm{ha}^{-1}\right)$ was recorded from D4G1, which was followed by D3G1 (1134 kg ha-1) while lowest seed yield was recorded from the D1G2 (859 $\mathrm{kg} \mathrm{ha}^{-1}$ ) followed by the treatment D2G2. The highest seed yield in D4G1 was attributed due to combined effect of number of pods plant ${ }^{-1}$ and 1000 -seed weight. 
Yeasmin et al.

Table 3. Interaction effect of genotype and density on seed yield and yield contributing characters of mungbean genotypes

\begin{tabular}{l|c|c|c|c}
\hline Interaction & $\begin{array}{c}\text { No. of seed } \\
\text { pod }^{-1}\end{array}$ & $\begin{array}{c}\text { No. of pods } \\
\text { plant }^{-1}\end{array}$ & $\begin{array}{c}\text { 1000- seed wt. } \\
\text { (gm) }\end{array}$ & $\begin{array}{c}\text { Seed yield } \\
\left(\mathrm{kg} \mathrm{ha}^{-1}\right)\end{array}$ \\
\hline $\mathrm{D}_{1} \mathrm{G}_{1}$ & 11.77 & 8.49 & 47.24 & 991.50 \\
$\mathrm{D}_{1} \mathrm{G}_{2}$ & 10.60 & 7.93 & 45.79 & 859.10 \\
$\mathrm{D}_{1} \mathrm{G}_{3}$ & 12.20 & 7.21 & 45.36 & 944.90 \\
$\mathrm{D}_{2} \mathrm{G}_{1}$ & 11.50 & 10.22 & 49.92 & 1020.00 \\
$\mathrm{D}_{2} \mathrm{G}_{2}$ & 11.23 & 8.65 & 49.87 & 921.40 \\
$\mathrm{D}_{2} \mathrm{G}_{3}$ & 12.10 & 9.74 & 47.91 & 1022.90 \\
$\mathrm{D}_{3} \mathrm{G}_{1}$ & 11.60 & 11.18 & 51.92 & 1133.50 \\
$\mathrm{D}_{3} \mathrm{G}_{2}$ & 11.40 & 10.04 & 50.91 & 994.50 \\
$\mathrm{D}_{3} \mathrm{G}_{3}$ & 11.80 & 10.54 & 48.06 & 1051.40 \\
$\mathrm{D}_{4} \mathrm{G}_{1}$ & 11.63 & 12.03 & 51.51 & 1230.00 \\
$\mathrm{D}_{4} \mathrm{G}_{2}$ & 11.33 & 10.33 & 51.36 & 1004.60 \\
$\mathrm{D}_{4} \mathrm{G}_{3}$ & 10.97 & 10.87 & 46.58 & 1107.90 \\
\hline $\mathrm{CV}(\%)$ & 3.81 & 9.90 & 3.20 & 2.68 \\
$\mathrm{LSD}(0.05)$ & 0.74 & 1.64 & 2.65 & 46.39 \\
\hline
\end{tabular}

$\mathrm{G}_{1}: \mathrm{GK} 24, \mathrm{G}_{2}: \mathrm{GK} 63, \mathrm{G}_{3}: \mathrm{BU} \operatorname{mug} 4, \mathrm{D}_{1}: 15 \mathrm{~cm} \times 10 \mathrm{~cm}, \mathrm{D}_{2}: 20 \mathrm{~cm} \times 10 \mathrm{~cm}, \mathrm{D}_{3}: 25 \mathrm{~cm} \times 10 \mathrm{~cm}$ and $\mathrm{D}_{4}$ : $30 \mathrm{~cm} \times 10 \mathrm{~cm}$

\section{Conclusion}

Considering the results of this study it could be concluded that genotype, GK 24 yielded higher than GK 63 and BU mug4, but $30 \mathrm{~cm}$ x $10 \mathrm{~cm}$ spacing was found the most suitable one among the tested four spacing. Overall, GK 24 genotype performed better in all respects of yield and yield attributes at $30 \mathrm{~cm} \times 10 \mathrm{~cm}$ spacing.

\section{References}

Allard, M. and M. A. Q. Sheikh. 1990. Variability and correlation studies in summer mungbean (Vigna radiata L.). Bangladesh Agric. 12: 63-67.

BBS. 2013. Statistical Yearbook of Bangladesh. Bangladesh Bureau of Statistics. Vol. 2, No. 2.

Eisemann, L. T. 1990. The physiological basis of crop yield. In: L. T. Evans (ed.). Crop Physiology-Some case histories. Cambridge University Press, Cambridge. Pp. 345.

Gupta, V. S. 1998. Crop Improvement.Vol. 1. Physiological attributes. Oxford and IBH, New Delhi. Pp. 131-142.

Rubio, J., J. I. Cubero, L. M. Suso and F. Flores. 2004. Biplot analysis of trait relation of white lupin in Spain. Euphytica. 135: 217-224.

Sarkar, A. R., H. Kabir, M. Begum and A. Salam, 2004. Yield performance of mungbean as affected by planting date, variety and plant density. J. Agron. 3: 18-24.

Sultana, S. 2014. Genotype environment interaction in quality seed production of mungbean. M. S. Thesis. Seed Science and Technology Unit, BSMRAU. 
Effect of Genotype and Density on the Productivity of Mungbean

Yimram, T., P. Somta and P. Srinives. 2009. Genetic variation in cultivated mungbean germplasm and its implication in breeding for high yield. Field Crops Res. 112: 260-266. 